\title{
The impact of methods for estimating bone health and the global burden of bone disease
}

\author{
Zoë A Cole, MRCP, (I) Elaine M Dennison, PhD, (I) Cyrus Cooper, FMedSci. (I)
}

\section{Cole ZA, Dennison EM, Cooper C. The impact of methods for estimating bone health and the global burden of bone disease Salud Publica Mex 2009;5 I suppl I:S38-S45.}

\begin{abstract}
Osteoporosis constitutes a major public health problem through its association with age related fractures. Fracture rates are generally higher in caucasian women than in other populations. Important determinants include estrogen deficiency in women, low body mass index, cigarette smoking, alcohol consumption, poor dietary calcium intake, physical inactivity, certain drugs and illnesses. Thus, modification of physical activity and dietary calcium/vitamin D nutrition should complement high risk approaches. In addition, the recently developed WHO algorithm for evaluation of I0-year absolute risk of fracture provides a means whereby various therapies can be targeted cost-effectively to those at risk. Risk factors, together with bone mineral density (BMD) and biochemical indices of bone turnover, can be utilised to derive absolute risks of fracture and cost-utility thresholds at which treatment is justified. These data will provide the basis for translation into coherent public health strategies aiming to prevent osteoporosis both in individuals and in the general population.
\end{abstract}

Key words: osteoporosis; fracture risk; prevention; bone density; risk factors; WHO algorithm; absolute risk of fracture; public health
Cole ZA, Dennison EM, Cooper C.

Impacto de los métodos para medir la salud ósea

y la carga global de enfermedades óseas.

Salud Publica Mex 2009;5 I supl I:S38-S45.

\section{Resumen}

La osteoporosis constituye un importante problema de salud pública debido a su asociación con fracturas relacionadas con la edad. Las tasas de fractura generalmente son más altas en mujeres caucásicas que en otros grupos poblacionales. Los principales determinantes incluyen deficiencia de estrógeno en mujeres, bajo índice de masa corporal, consumo de tabaco y alcohol, escaso consumo de calcio, inactividad física y algunas drogas y enfermedades. De este modo, la modificación de la actividad física y el consumo de nutrimentos con calcio y vitamina $D$ deben complementar los tratamientos en alto riesgo. Además, el recientemente desarrollado algoritmo de la OMS para la evaluación de riesgo de fractura absoluto a 10 años constituye una herramienta que permite plantear eficientemente diversas terapias a aquellos que están en riesgo. Los factores de riesgo, junto con la densidad mineral ósea y los índices bioquímicos de regeneración ósea pueden utilizarse para obtener riesgos de fractura absolutos así como umbrales costo-utilidad que justifiquen el tratamiento. Estos datos proveerán una base para su traducción en estrategias de salud pública con la finalidad de prevenir la osteoporosis tanto en los individuos como en la población en general.

Palabras clave: osteoporosis; riesgo de fractura; prevención; densidad ósea; factores de riesgo; algoritmo de la OMS; riesgo de fractura absoluto; salud pública 
$\mathrm{O}$ steoporosis is a systemic disorder characterised by low bone mass and micro-architectural deterioration of bone tissue with a consequent increase in bone fragility and susceptibility to fracture. ${ }^{1}$ It has a huge impact on public health through the increased morbidity, mortality and economic costs associated with fractures. Historically the definition of osteoporosis has been difficult. A definition based on bone mineral density (BMD) may not encompass all the risk factors for fracture, whereas a fracture based definition will not enable identification of at risk populations. In 1994, the World Health Organisation (WHO) convened to resolve this issue, defining osteoporosis in terms of fracture and BMD. ${ }^{2}$ It is important to note that this only takes into account the deterioration in mineralisation, and does not reflect the decline in micro architecture. More recently, there has been a move towards assessment of individualised 5 or 10 year absolute risk. ${ }^{3}$ This has the advantage of incorporating risk factors that are partly independent of $\mathrm{BMD}$, such as age and previous fracture, and thus allows decisions regarding commencement of therapy to be made more readily. This article reviews the global epidemiology of osteoporosis as well as methods to diagnose this disabling condition.

\section{Fracture epidemiology}

Fractures of the hip, vertebral body and distal forearm have long been regarded as the typical osteoporotic fractures. Prospective studies have shown that there is a heightened risk of almost all types of fracture in individuals with low bone density irrespective of fracture site. In the year 2000 there were an estimated 9 million osteoporotic fractures of which 1.6 million were at the hip, 1.7 million at the forearm and 1.4 million were clinical vertebral fractures. Worldwide, osteoporotic fractures accounted for $0.83 \%$ of the global burden of non-communicable disease and $1.75 \%$ in Europe. In Europe, osteoporotic fractures accounted for more disability adjusted life years (DALYs) than many other chronic non communicable diseases ${ }^{4}$ (figure 1 ).

A study of British fracture occurrence indicates that the population risk is similar in the UK. Thus one in two women that are 50 years of age will have an osteoporotic fracture in their remaining lifetime; the figure for men is one in five. ${ }^{5}$ The combined annual costs of all osteoporotic fractures have been estimated to be $\$ 20$ billion in the USA and $\$ 30$ billion in the European Union. ${ }^{6}$ Fracture incidence in the community is bimodal, showing peaks in youth and the very elderly (figure 2 ). In young people, fractures of the long bones predominate, usually after substantial trauma, and they are more frequent in males than females. Over the age of 35 years fracture incidence in women rises steeply so that rates become twice those in men. World wide elderly people represent the fastest growing age group, and the yearly number of fractures is likely to rise substantially with continued aging of the population.

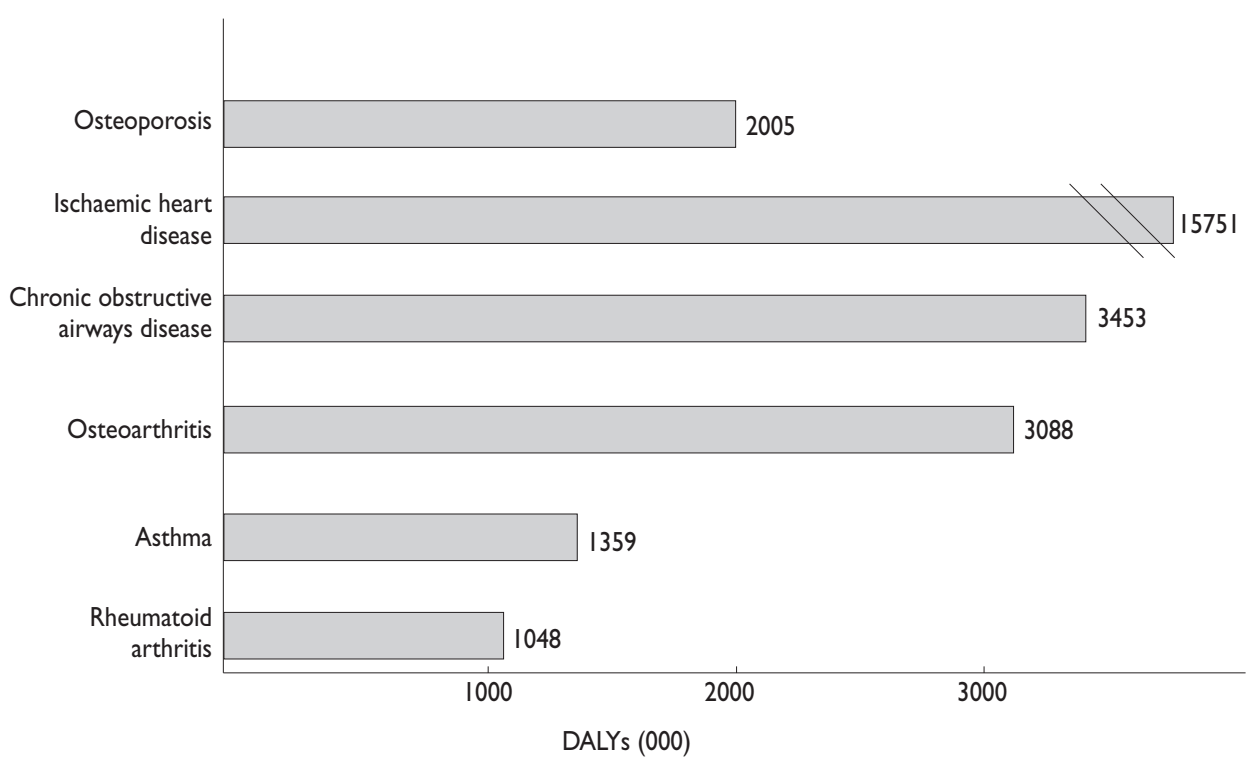

Figure I: Disability adjusted life yeARs (DALYs) LOST dUe to A SELECTION OF NON-COMMUNICABLE DISEASES IN EuROPE. (Adapted from Johnell O. Kanis J.) ${ }^{4}$ 


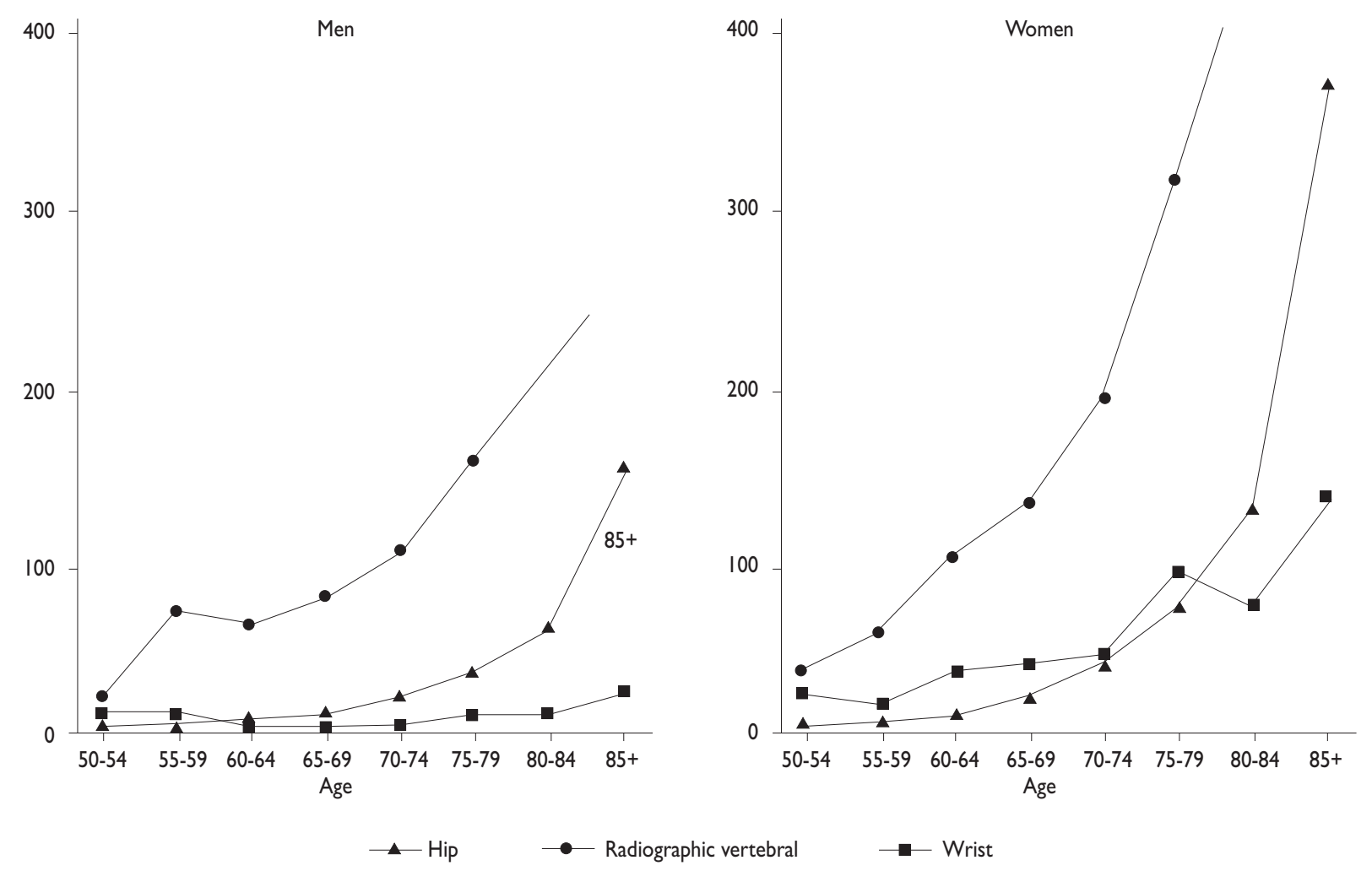

Figure 2: RAdiographic VerTebral, HIP AND WRIST FRACTURE INCIDENCE by AGE AND GENDER ${ }^{5}$

\section{Hip fracture}

Hip fractures are the most devastating result of osteoporosis: they require the patient to be admitted to hospital and cause significant morbidity and mortality. Most hip fractures take place after a fall from standing height, $80 \%$ occur in women and $90 \%$ in people older than 50 years. The incidence increases exponentially with age (figure 1) as a result of age related decrease in bone mass at the proximal femur and the age related increase in falls. Worldwide there were an estimated 1.66 million hip fractures in 1990. This has been estimated to rise to 6.3 million by 2050 with the increasing number of elderly people in the population. ${ }^{7}$ The lifetime risk of hip fracture for 50 year olds in the UK is $11.4 \%$ and $3.1 \%$ for women and men respectively. Most of this risk is accrued in old age, such that a 50 year old woman's 10 year risk of hip fracture is $0.3 \%$ rising to $8.7 \%$ when she is 80 years old. The corresponding figures for men are 0.2 and $2.9 \%$ respectively. ${ }^{5}$

Hip fracture mortality is higher in men than women and increases with age..$^{8}$ It is greatest in those with co- existing illnesses and poor pre-fracture function. The risk of death is greatest after fracture and decreases gradually with time. In the United Kingdom the 12 month survival for hip fracture for men is $63.3 \%$ versus 90.0\% expected and for women $74.9 \%$ versus $91.1 \%$ expected. ${ }^{5}$ Hip fractures result in significant morbidity. Patients are prone to developing complications such as pressure sores and bronchopneumonia. Fifty percent of those ambulatory before the fracture are unable to walk independently afterward. Age is an important determinant of outcome, with $14 \%$ of 50-55 year old hip fracture patients being discharged to nursing homes versus 55\% of those aged $>90$ years old. ${ }^{9}$

\section{Vertebral fracture}

Only about a third of all radiographically identified vertebral deformities come to specialist attention. There is also disagreement about the radiographic definition of deformities in those that do present. Thus in studies using radiographic screening of populations, vertebral deformities have been estimated to be three times that 
of hip fracture. Data from the prospective European Vertebral Osteoporosis Study (EVOS) have allowed accurate assessment of radiographically determined vertebral factures in a large population. ${ }^{10}$ The overall age adjusted incidence of vertebral fractures was 5.7/1000 person years for men and 10.7/1000 person years for women. The age standardised prevalence was $12.2 \%$ for men and $12.0 \%$ for women $50-79$ years old. Historically it was believed that vertebral fractures were more common in women, but the EVOS data suggest that this is not the case at younger ages, possibly because of a higher incidence of trauma in men (figure 3). Only around a quarter of vertebral fractures result from falls, most result from routine activities such as bending or lifting light objects. ${ }^{11}$ In contrast to hip fractures, excess mortality after vertebral fracture seems to increase progressively after diagnosis of fracture. In the UK the observed survival in women 12 months after fracture was $86.5 \%$ versus $93.6 \%$ expected. At 5 years it was $56.5 \%$ observed and $69.9 \%$ expected. ${ }^{5}$ The impact of a single vertebral fracture may be low but multiple fractures can cause progressive loss of height and kyphosis and severe back pain in the acute stages. Quality of life scores decrease as the number of vertebral fractures increases. $^{12}$

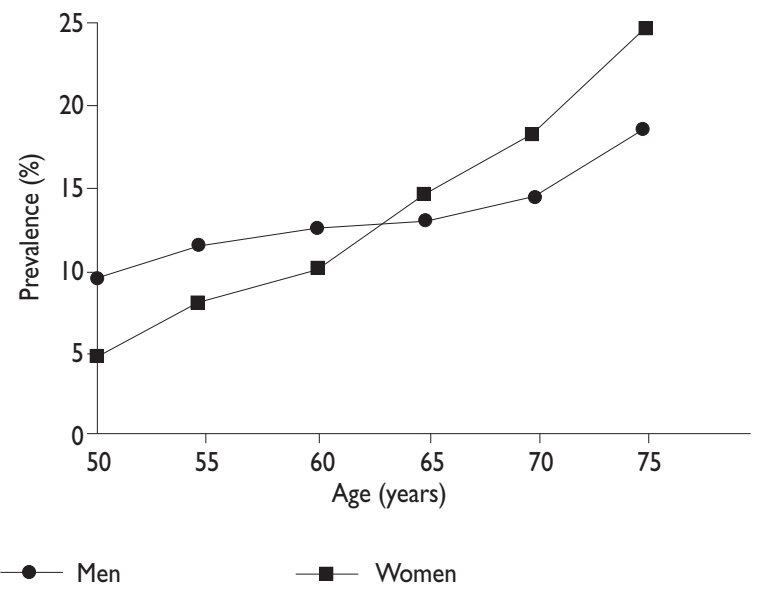

O’Neill et al, 1996

Figure 3: Prevalence of Vertebral deformity by Gender. Data derived from the European Vertebral Osteoporosis Survey. (Reproduced from J Bone Miner Res WITH PERMISSION OF THE AMERICAN SOCIETY FOR BONE AND Mineral Researchi) ${ }^{10}$

\section{Distal forearm fracture}

Wrist fractures show a different pattern of occurrence to hip and vertebral fractures. Incidence increases in white women between the ages of 45 and 60 years, followed by a plateau. This may relate to altered neuromuscular reflexes with ageing, and as a result, a tendency to fall sideways or backwards, and thus not to break the fall with an outstretched arm. Most wrist fractures occur in women and 50\% occur in women over 65 years old. Data from the GPRD show that a woman's lifetime risk of wrist fracture at 50 years old is $16.6 \%$, falling to $10.4 \%$ at 70 years. The incidence in men is low and does not rise much with ageing (lifetime risk $2.9 \%$ at age 50 years and $1.4 \%$ at age 70 years). ${ }^{5}$ Wrist fractures do not seem to increase mortality although wrist fractures may impact on some activities such as writing or meal preparation.

\section{Clustering of fractures in individuals}

Epidemiological studies suggest that patients with different types of fragility fractures are at increased risk of developing other types of fracture. For example, the presence of a previous vertebral deformity leads to a 7 to 10 fold increase in the risk of subsequent vertebral deformities. ${ }^{13}$ This is a comparable level of increased risk to that seen for individuals who have sustained one hip fracture to then sustain a second. Furthermore, data from Rochester, Minnesota, suggest that the risk of a hip fracture is increased 1.4 fold in women and 2.7 fold in men after the occurrence of a distal forearm fracture. ${ }^{14}$ The corresponding figures for subsequent vertebral fracture are 5.2 and 10.7 .

\section{Time trends and future projections}

Life expectancy is increasing around the globe and the number of elderly individuals is rising in every geographic region. The world population is expected to rise from the current 323 million individuals aged 65 years or over, to 1555 million by the year 2050. These demographic changes alone can be expected to increase the number of hip fractures occurring among people aged 35 years and over worldwide: the incidence is estimated to rise from 1.66 million in 1990 to 6.26 million in 2050. ${ }^{7}$ Assuming a constant age-specific rate of fracture, as the number of over $65 \mathrm{~s}$ increases from 32 million in 1990 to 69 million in 2050, the number of hip fractures in the US will increase threefold. ${ }^{7}$ In the UK, the number of hip fractures may increase from 46000 in 1985 to 117000 in $2016 .{ }^{15}$ An increasingly elderly 
population in Latin America and Asia could lead to a shift in the geographical distribution of hip fractures, with only a quarter occurring in Europe and North America $^{7}$ (figure 4). Such projections are almost certainly optimistic considering that increases in the incidence of hip fractures have been observed even after adjusting for the growth in the elderly population. Age-adjusted rate of hip fracture appears to have levelled off in the northern regions of the USA, in parts of Sweden, and the $\mathrm{UK}$, there is some evidence to suggest that since implementation of osteoporosis screening and treatment programs, the incidence of age adjusted hip fractures are now starting to fall. ${ }^{16,17}$ However fracture rates are still rising in some locales ${ }^{18}$ and subsets of the population. ${ }^{19}$ These discrepancies in secular trends by race, gender and age might help identify novel public health measures.

\section{Geography}

There is a substantial variation in hip fracture rates between populations of a given race or gender. Age adjusted rates are highest in Scandinavian and North American populations, with almost seven fold lower rates in southern European countries. ${ }^{20}$ Hip fracture rates are also lower in Asian and Latin American populations $s^{21,22}$ and rates seem to be lower in rural areas rather than urban areas in any country. ${ }^{23,24}$ These findings suggest an important role for environmental factors in the aetiology of hip fracture. However, factors studied so far including smoking, alcohol consumption, activity levels, obesity and migration status have failed to explain these trends. The EVOS study demonstrated a threefold difference in the prevalence of vertebral deformities between countries, with the highest rates in Scandinavia. The prevalence range between centres was 7.5-19.8\% for men and 6.2-20.7\% for women. The differences were not as great as those seen for hip fracture in Europe, some of the differences could be explained by levels of physical activity and body mass index. ${ }^{8}$

\section{Methods to assess bone health}

\section{Dual energy X ray absorptiometry}

Dual energy $X$ ray absorptiometry (DXA) employs $X$ rays of two energies to produce a projection image of the region of interest. From these projection images two measures are calculated to determine bone mass: areal bone mineral density $\left(\mathrm{g} / \mathrm{cm}^{2}\right)$ and bone mineral content (BMC) (g). Studies of DXA measures have confirmed that $\mathrm{BMC}$ and to a lesser degree BMD is strongly correlated to

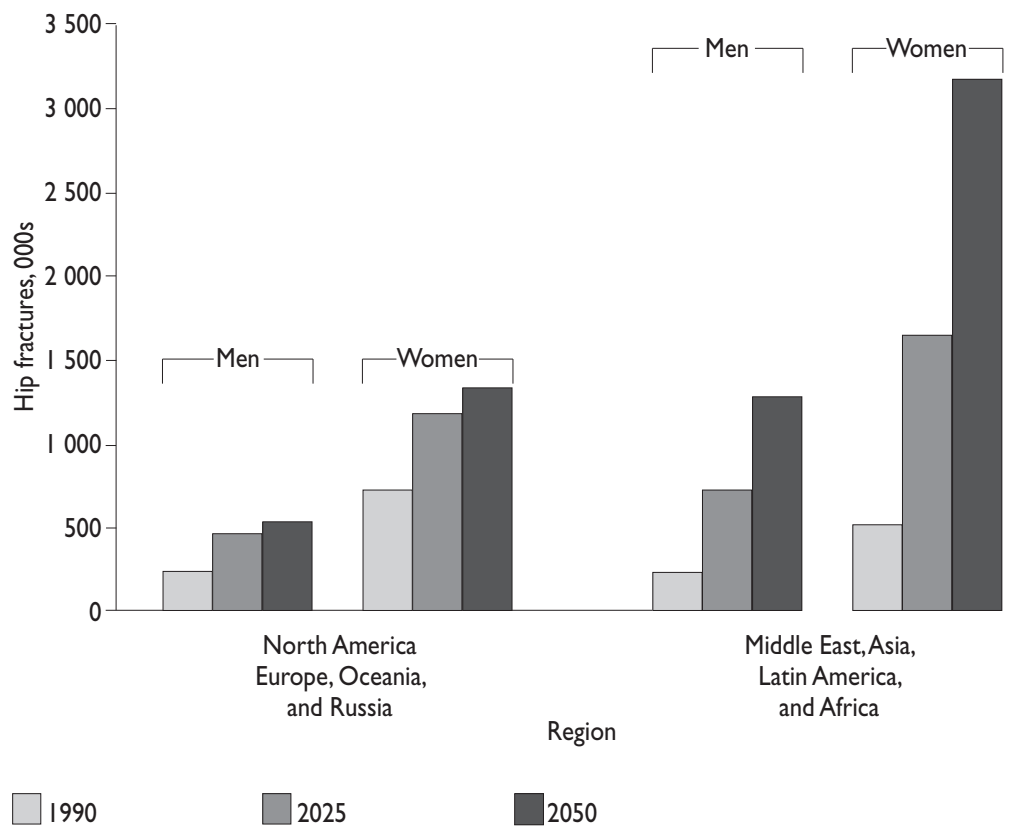

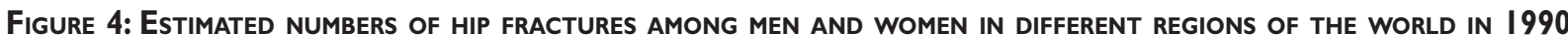
AND $2050^{7}$ 
ash weight. ${ }^{25}$ DXA is commonly performed at the lumbar spine and proximal femur. However it can also be measured at the forearm, the calcaneus and the total body. The choice of the appropriate site is based on purpose of the measurement and the technology of the equipment used. Commercial DXA devices are either general purpose instruments for bone densitometry examinations of the axial and peripheral skeleton or peripheral units for scans of the forearm and / or calcaneus. The advantages of DXA include low radiation dose, low cost, ease of use and rapidity of measurement. Peripheral DXA devices are being increasingly utilized for BMD measurements at the forearm and calcaneus. ${ }^{26}$ They can be used as a pre-selection tool to identify women with low BMD at the axial skeleton, thus enabling reduction of the number of individuals who need evaluation with axial DXA. ${ }^{27}$ These peripheral devices have the advantages of low cost and portability. There are however limitations inherent to DXA measurements. This two dimensional technique can not determine between cortical and trabecular bone, and cannot discriminate changes due to bone geometry (e.g. increases in the third dimension) from those purely due to increased bone density (within a fixed volume of bone). Falsely elevated BMD values at the spine can occur in patients with degenerative spinal changes, fractures in lumbar vertebrae, scoliosis or aortic calcification. There is still controversy as to which site could better estimate the risk of low energy fracture. Meta-analysis results indicate that $\mathrm{BMD}$ measurements at the hip are superior in predicting hip fractures compared to BMD measurements at other sites. ${ }^{28}$ The World Health Organisation defines osteoporosis by a $\mathrm{T}$ score more than $2 \mathrm{SD}$ below the peak bone mass; these WHO criteria were developed for DXA measurements at the lumbar spine hip or forearm.

\section{Quantitative computed tomography}

Quantitative computed tomography (QCT) provides an alternative to DXA for the measurement of spine, hip and wrist BMD. Quantification of BMD by QCT, like DXA, is based on the attenuation of the $X$ ray beam as it passes through the body. Each slice in CT represents tissue volume and thus a volumetric BMD can be attained. This is an advantage in studies with children and adolescents where DXA may underestimate BMD due to the growth-related variations in bone size. The other main advantage of QCT is its ability to assess separately cortical and trabecular bone. Compared to DXA, QCT provides similar or better results in prediction of spinal fracture in that the effects of degenerative disease or aortic calcification can be excluded. ${ }^{29} \mathrm{QCT}$ has not been used widely in clinical practice because of its high cost hardware, the increased demand for CT whole body examinations in a clinical environment and the higher radiation dose relative to DXA.

\section{Peripheral quantitative computed tomography}

A recent development in QCT technology is the availability of peripheral scanners (pQCT). These scanners provide three dimensional mineralisation data in appendicular sites, commonly the distal radius and distal tibia. As with traditional QCT, trabecular and cortical compartments can be isolated and studied individually. Additionally they present a lower radiation dose to the central body scans. The main advantage is the low investment and running costs. PQCT measurement at the distal radius showed moderate correlation with BMD at the hip and spine. ${ }^{30,31}$ The greatest advantage of the machines is the ability to image at a resolution that allows for trabecular visualisation allowing for differences to be picked up in osteopenic women that have fractured at the wrist compared to those without, ${ }^{32}$ DXA is unable to differentiate between these groups.

\section{Quantitative ultrasound}

Quantitative ultrasound(QUS) has been introduced recently for measuring bone density in the appendicular skeleton. Measurements are performed primarily at the calcaneus. It is a technique that uses non-ionising sound waves to detect mineral density. Transducers transmit ultrasound energy that travels through the bone to the receiving transducer. Two measures are produced: Broadband ultrasound attenuation (BUA) and speed of sound (SOS). QUS measures are well correlated with BMD derived from calcaneal DXA scans, and can discriminate healthy from osteoporotic groups. ${ }^{33}$ However a significant false negative rate has been detected. Several studies have documented the ability of QUS measurements to estimate fracture risk. ${ }^{34,35} \mathrm{~A}$ recent study has suggested that BUA predicts osteoporotic fractures better than DXA and independently of BMD. ${ }^{36}$ Interest in QUS methods can be attributed primarily to the fact that they involve no radiation exposure. Additionally they are inexpensive and portable. The main disadvantage is lack of sensitivity, ${ }^{37}$ making it inappropriate for long term monitoring of osteoporosis. Currently ultrasound assessment is used as a screening tool, with confirmation of diagnosis via DXA evaluation. 


\section{Biochemical markers}

Several serum and urine biochemical markers of bone turnover have been developed. These provide noninvasive and fairly inexpensive methods for assessing rates of bone formation and resorption in vivo. The most widely available markers include serum bone specific alkaline phosphatase and the amino terminal propeptide of type 1 procollagen, which are markers of bone formation, and urine or serum telopeptides of collagen crosslinks, which are the markers for bone resorption. Disadvantages include their indication of whole body bone turnover (mainly cortical bone) and day-to-day variability. Despite drawbacks these markers can be used to study the pathogenesis of osteoporosis, predict the risk of future fracture and predict and monitor response to therapy. Prospective studies have shown an association of osteoporotic fracture with indices of bone turnover independent of BMD in menopausal and elderly women. ${ }^{38}$ In elderly women with values for resorption markers exceeding the reference range for premenopausal women, fracture risk is increased two fold after adjustment for BMD, thus a combined approach could improve fracture prediction. ${ }^{39}$

\section{Assessment of fracture risk}

The WHO scientific group recently convened to develop more ways to assess fracture risk. The rationale for this initiative is that $\mathrm{T}$ scores are insufficient to predict fracture risk. Although the T score has many good attributes: it is simple and widely used, it has good correlation with fracture risk and it can detect some high risk patients. ${ }^{2}$ Its shortcomings include lack of standardisation regarding which skeletal sites to evaluate, lack of generalisation to non Caucasian groups and use of BMD as the only risk factor evaluated. Inappropriate T score thresholds for osteoporosis treatment have incorrectly identified patients who are not at high risk of fractures whilst missing many who are at increased risk. ${ }^{40}$ Several other clinical risk factors contribute to fracture risk, in part independently of BMD. These include age, prior fragility fracture, premature menopause, a family history of hip fracture and the use of corticosteroids. Since several of these risk factors are partly independent on BMD, their use in conjunction with BMD improves sensitivity of fracture prediction without adverse effects on specificity. The combined use of these risk factors along with age and BMD can be used in multivariate models to estimate the 10 year probability of hip and other fractures. ${ }^{41}$ Thus a woman at age 60 years with an average BMD (about-1.4) has an average 10 year probability of hip fracture at around $2.4 \%$. If she has previously had a fragility fracture this risk increased to $4.8 \%$. Intervention thresholds will be set by the global cost effectiveness model allowing individual countries to determine how to utilise these interventions. The WHO initiative have concluded from recent population based studies that clinical risk factors can be used to enhance the performance characteristics of BMD. However application of these models will require the incorporation of hazard functions of death and calibration to the epidemiology of specific countries. ${ }^{42}$

\section{Conclusion}

Osteoporosis is a disease that has a huge impact on global public health. The impact of osteoporotic fracture is massive, not just for individuals, but for the health service economy, and population as a whole. The characterisation of some of the risk factors for osteoporotic fractures have been elucidated, as a result the assessment of patients at high risk of fracture can be identified by use of algorithms and appropriate preventative and therapeutic strategies implemented.

\section{References}

I. Consensus development conference: prophylaxis and treatment of osteoporosis. Osteoporos Int 1991; I: | |4-I | 17.1991.

2. Assessment of fracture risk and its application to screening for postmenopausal osteoporosis. Report of a WHO Study Group. World Health Organ Tech Rep Ser 1994; 843: I- 29.

3. Kanis JA, Johnell O, Oden A, Dawson A, De Laet C, Jonsson B. Ten year probabilities of osteoporotic fractures according to $B M D$ and diagnostic thresholds. Osteoporos Int 200 I; I2(I2):989-995.

4. Johnell $O$, Kanis JA. An estimate of the worldwide prevalence and disability associated with osteoporotic fractures. Osteoporos Int 2006; I7(I2): I726-I733.

5. van Staa TP, Dennison EM, Leufkens HG, Cooper C. Epidemiology of fractures in England and Wales. Bone 2001; 29(6):517-522.

6. Cummings SR, Melton LJ. Epidemiology and outcomes of osteoporotic fractures. Lancet 2002; 359(9319): 1761-1767.

7. Cooper C, Campion G, Melton LJ, III. Hip fractures in the elderly: a world-wide projection. Osteoporos Int 1992; 2(6):285-289.

8. Cooper C,Atkinson EJ, Jacobsen SJ, O'Fallon WM, Melton LJ, III. Population-based study of survival after osteoporotic fractures.Am J Epidemiol 1993; 137(9): 100 I-1005.

9. Chrischilles EA, Butler CD, Davis CS, Wallace RB.A model of lifetime osteoporosis impact. Arch Intern Med I99I; I5I(10):2026-2032. 10. O'Neill TW, Felsenberg D, Varlow J, Cooper C, Kanis JA, Silman AJ. The prevalence of vertebral deformity in european men and women: the European Vertebral Osteoporosis Study.J Bone Miner Res 1996; II (7):1010-1018.

I I. Cooper C,Atkinson EJ, O'Fallon WM, Melton LJ, III. Incidence of clinically diagnosed vertebral fractures: a population-based study in Rochester, Minnesota, 1985-1989.J Bone Miner Res 1992; 7(2):22I-227. 12. Oleksik A, Lips P, Dawson A, Minshall ME, Shen W, Cooper C et al. Health-related quality of life in postmenopausal women with low BMD 
with or without prevalent vertebral fractures. J Bone Miner Res 2000; 15(7):1384-1392

13. Ross PD, Davis JW, Epstein RS, Wasnich RD. Pre-existing fractures and bone mass predict vertebral fracture incidence in women. Ann Intern Med 1991; I | 4(II):919-923.

I4. Cuddihy MT, Gabriel SE, Crowson CS, O'Fallon WM, Melton LJ, III. Forearm fractures as predictors of subsequent osteoporotic fractures. Osteoporos Int 1999; 9(6):469-475.

15. Royal College of Physicians. Fractured neck of femur: prevention and management. Summary and report of the Royal College of Physicians.

J R Coll Physicians Lond 1989; 23:8-12.

16. Kannus P, Niemi S, Parkkari J, Palvanen M,Vuori I, Jarvinen M. Nationwide decline in incidence of hip fracture.J Bone Miner Res 2006; 2I(I2):1836-1838.

17. Jaglal SB, Weller I, Mamdani M, Hawker G, Kreder H, Jaakkimainen L, et al. Population trends in BMD testing, treatment, and hip and wrist fracture rates: are the hip fracture projections wrong? J Bone Miner Res 2005; 20(6):898-905.

18. Hagino H, Katagiri H, Okano T, Yamamoto K, Teshima R. Increasing incidence of hip fracture in Tottori Prefecture, Japan: trend from 1986 to 200I. Osteoporos Int 2005; I6(I2):1963-1968.

19. Zingmond DS, Melton LJ, III, Silverman SL. Increasing hip fracture incidence in California Hispanics, 1983 to 2000. Osteoporos Int 2004; 15(8):603-6I0.

20. Johnell O, Gullberg B,Allander E, Kanis JA. The apparent incidence of hip fracture in Europe: a study of national register sources. MEDOS Study Group. Osteoporos Int 1992; 2(6):298-302.

21.Yan L, Zhou B, Prentice A, Wang X, Golden MH. Epidemiological study of hip fracture in Shenyang, People's Republic of China. Bone 1999; 24(2): $15 \mid-155$.

22. Morales-Torres J, Gutierrez-Urena S. The burden of osteoporosis in Latin America. Osteoporos Int 2004; I5(8):625-632.

23. Kaastad TS, Meyer HE, Falch JA. Incidence of hip fracture in Oslo, Norway: differences within the city. Bone 1998; 22(2): 175- 178. 24. Sanders KM, Nicholson GC, Ugoni AM, Seeman E, Pasco JA, Kotowicz MA. Fracture rates lower in rural than urban communities: the Geelong Osteoporosis Study.J Epidemiol Community Health 2002; 56(6):466-470. 25. Sran MM, Khan KM, Keiver K, Chew JB, McKay HA, Oxland TR. Accuracy of DXA scanning of the thoracic spine: cadaveric studies comparing BMC, areal BMD and geometric estimates of volumetric BMD against ash weight and CT measures of bone volume. Eur Spine J 2005; I4(I0):97|-976.

26. Adams JE. Dual-energy $X$ ray absorptiometry. In: Gramp S, editor. Radiology of Osteoporosis. New York: Springer, 2003.

27. Damilakis J, Papadokostakis G, Perisinakis K, Hadjipavlou A, Gourtsoyiannis N. Can radial bone mineral density and quantitative ultrasound measurements reduce the number of women who need axial density skeletal assessment? Osteoporos Int 2003; 14(8):688-693. 28. Marshall D, Johnell O,Wedel H. Meta-analysis of how well measures of bone mineral density predict occurrence of osteoporotic fractures. BMJ 1996; 312(704I):I254-I259.
29. Lang TF, Guglielmi G, van KC, De SA, Cammisa M, Genant HK. Measurement of bone mineral density at the spine and proximal femur by volumetric quantitative computed tomography and dual-energy X-ray absorptiometry in elderly women with and without vertebral fractures. Bone 2002; 30(I):247-250.

30. Gatti D, Rossini M, Zamberlan N, Braga V, Fracassi E,Adami S. Effect of aging on trabecular and compact bone components of proximal and ultradistal radius. Osteoporos Int 1996; 6(5):355-360.

31. Grampp S, Lang P, Jergas M, Gluer CC, Mathur A, Engelke K et al. Assessment of the skeletal status by peripheral quantitative computed tomography of the forearm: short-term precision in vivo and comparison to dual X-ray absorptiometry.J Bone Miner Res 1995; I0(I0):I566-I576. 32. Boutroy S, Bouxsein ML, Munoz F, Delmas PD. In vivo assessment of trabecular bone microarchitecture by high-resolution peripheral quantitative computed tomography.J Clin Endocrinol Metab 2005; 90(12):6508-6515.

33. Hans D, Molina P, Schott AM, Sebert JL, Cormier C, Kotzki PO et al. Ultrasonographic heel measurements to predict hip fracture in elderly women: the EPIDOS prospective study. Lancet 1996;348(9026): 5||$-5 \mid 4$.

34. Gluer CC, Eastell R, Reid DM, Felsenberg D, Roux C, Barkmann R et al. Association of five quantitative ultrasound devices and bone densitometry with osteoporotic vertebral fractures in a population-based sample: the OPUS Study. J Bone Miner Res 2004; 19(5):782-793.

35. Gluer CC, Hans D. How to use ultrasound for risk assessment: a need for defining strategies. Osteoporos Int 1999; 9(3): 193-195.

36. Stewart A, Kumar V, Reid DM. Long-term fracture prediction by DXA and QUS: a 10-year prospective study.J Bone Miner Res 2006; 2I(3): 4|3-4|8.

37. Moyad MA. Osteoporosis: a rapid review of risk factors and screening methods. Urol Oncol 2003; 2I(5):375-379.

38. Garnero P, Sornay-Rendu E, Claustrat B, Delmas PD. Biochemical markers of bone turnover, endogenous hormones and the risk of fractures in postmenopausal women: the OFELY study.J Bone Miner Res 2000; 15(8):1526-1536

39. Johnell O, Oden A, De Laet C, Garnero P, Delmas PD, Kanis JA. Biochemical indices of bone turnover and the assessment of fracture probability. Osteoporos Int 2002; 13(7):523-526.

40. Richards JB, Leslie WD, Joseph L, Siminoski K, Hanley DA, Adachi JD et al. Changes to osteoporosis prevalence according to method of risk assessment.J Bone Miner Res 2007; 22(2):228-234.

4I. Kanis JA, Borgstrom F, De Laet C, Johansson H, Johnell O, Jonsson B et al. Assessment of fracture risk. Osteoporos Int 2005; I6(6):58I-589. 42. Kanis JA, Oden A, Johnell O, Johansson H, De Laet C, Brown J et al. The use of clinical risk factors enhances the performance of BMD in the prediction of hip and osteoporotic fractures in men and women. Osteoporos Int 2007. 